\title{
It's not just science: challenges for public health intervention in Ebola epidemics in the Democratic Republic of Congo
}

\author{
Pengyan Wang ${ }^{1,2} \&$ William J. Liu ${ }^{1,2 *}$ \\ ${ }^{1}$ School of Laboratory Medicine and Life Sciences, Wenzhou Medical University, Wenzhou 325035, China; \\ ${ }^{2}$ NHC Key Laboratory of Biosafety, National Institute for Viral Disease Control and Prevention, Chinese Center for Disease Control and \\ Prevention, Beijing 102206, China
}

Received December 19, 2019; accepted March 2, 2020; published online March 10, 2020

Citation: Wang, P., and Liu, W.J. (2020). It's not just science: challenges for public health intervention in Ebola epidemics in the Democratic Republic of Congo. Sci China Life Sci 63, 1079-1081. https://doi.org/10.1007/s11427-019-1670-6

The Democratic Republic of Congo (DRC) is suffering from the world's second largest and most prolonged Ebola virus disease (EVD) epidemic on record (Figure 1). The current prevalence of EVD in the DRC makes this the 10th (and largest) EVD epidemic in the DRC since the first discovery of the Zaire Ebola virus in 1976 (Ilunga Kalenga, 2019). Globally, it is the second worst outbreak in the history of Ebola epidemics, and is only superceded by the EVD epidemic in West Africa from 2013 to 2016 (Liu, 2016). The EVD outbreak is occurring in the eastern provinces of North Kivu and Ituri in the DRC. According to the World Health Organization (WHO), at the peak of the outbreak in April 2019, there were approximately 300 new cases in 3 weeks. Since the outbreak was declared on 01 August 2018, more than 3,433 people have been diagnosed with EVD, with 3,310 confirmed cases and 2,253 deaths ("World Health Organization. Ebola virus disease-Democratic Republic of Congo. Disease Outbreak News", 20 February 2020, https:// www.who.int/csr/don/20-february-2020-ebola-drc/en/). This EVD epidemic has been recognized as the longest in the Middle African regions. Experts say it will be more difficult to contain the outbreak because the international borders between the outbreak site and Uganda, Rwanda, and South Sudan are porous, with unmanageable armed conflicts, armed groups, and large population crossings (Ilunga Ka-

*Corresponding author (email: liujun@ivdc.chinacdc.cn) lenga, 2019).

The WHO convened an emergency committee conference about the Ebola epidemic in the DRC on 17 July 2019, and they have announced that the current Ebola epidemic involving the 2018 outbreak in the DRC was a public health emergency of global concern. One immediate reason for the meeting was the first confirmed case in Goma, the capital of North Kivu province in the DRC. Goma is an important transportation hub with a large population density. If Ebola were to spread there, the consequences would be devastating.

As well as jeopardizing people's lives in Africa, the current Ebola epidemic has had other detrimental consequences. Population-flow, intractable armed conflicts, and organized attacks targeted at response groups occurred simultaneously. These things reduced the effectiveness of interventions, and they also exacerbated the spread of the disease. There were many fateful outcomes that threatened people's physical health, and there were broader effects, such as on democracy and economic growth in the DRC. Security incidents have created complex conditions and insurmountable obstacles for health workers battling the latest Ebola outbreak in the DRC.

The aims of public health interventions include the prevention of disease via evaluation, policy development, and safeguarding measures, and government intervention is irreplaceable in public health. People in the DRC have ignored warnings and failed to take timely action because they lack trust in international organizations, institutions, and the 
media, and they have doubts about the Ebola outbreak. Some families have refused to be monitored and treated by health workers, leading to the spread of the disease, and deaths (Nguyen, 2019). Compliance with government-imposed quarantine policies is indispensable for slowing the spread of the virus. In some cases, however, some of the mandatory measures to block the spread of the virus are counter to people's instincts to take care of the sick and respect the dead. As a result, not many people comply with these restrictions, and those who have difficulty finding treatment for common diseases may blame their plight on the epidemic and the caregivers. Public distrust makes public health care unsustainable, and this is considered a key factor in the spread of EVD across the region.

Violence and conflict in the region are further components of the current public EVD health crisis. The DRC has been the country most affected by this conflict since the mid1990s, particularly in the east. Prolonged conflict in North Kivu and Ituri provinces has hampered surveillance, contact tracing, and vaccination. In November 2019 two attacks occurred overnight on a shared living camp in Biakato Mines, and an Ebola response coordination office in Mangina. Four workers responding to the Ebola outbreak were killed and five others were injured (Mahase, 2019). Ebola responders face threats and attacks almost every day. These violent events jeopardize efforts to end the outbreak (Maxmen, 2019b). The continuing violence has led epidemiologists and Doctors Without Borders to suspend operations in these cities, and has hampered vaccination efforts (Maxmen, 2019b). The lack of medical services, poor sanitation, and malnutrition caused by the war could easily lead to a pandemic.

Despite challenges posed by mistrust and conflict, the government, the WHO, other countries, and international organizations are engaged in practical efforts to warn susceptible people, prevent infection, and treat known cases. Epidemiologists in the DRC have established an alert system that includes reporting of potential cases, and investigation and tracking by rapid response groups, measures that can reportedly bring an outbreak under control relatively rapidly (Moran, 2018). The experimental Ebola vaccine rVSV-ZEBOV has been used to protect against EVD via a ring vaccination strategy. More than 236,000 people have been vaccinated with rVSV-ZEBOV, including more than 60,000 health and frontline workers in the DRC and in Uganda, South Sudan, Rwanda, and Burundi. In addition to rVSVZEBOV, other Ebola vaccines are also under consideration for usage in field (Li et al., 2017; Suschak and Schmaljohn, 2019). Currently used drugs include the antibodies MAb114, ZMapp, REGN-EB3, and the antiviral drug remdesivir (Maxmen, 2019a). Other drugs include membrane fusion inhibitors, nucleoside analogs, and cytokine inhibitors (Murray, 2015). Both MAb114 and REGN-EB3 have proved

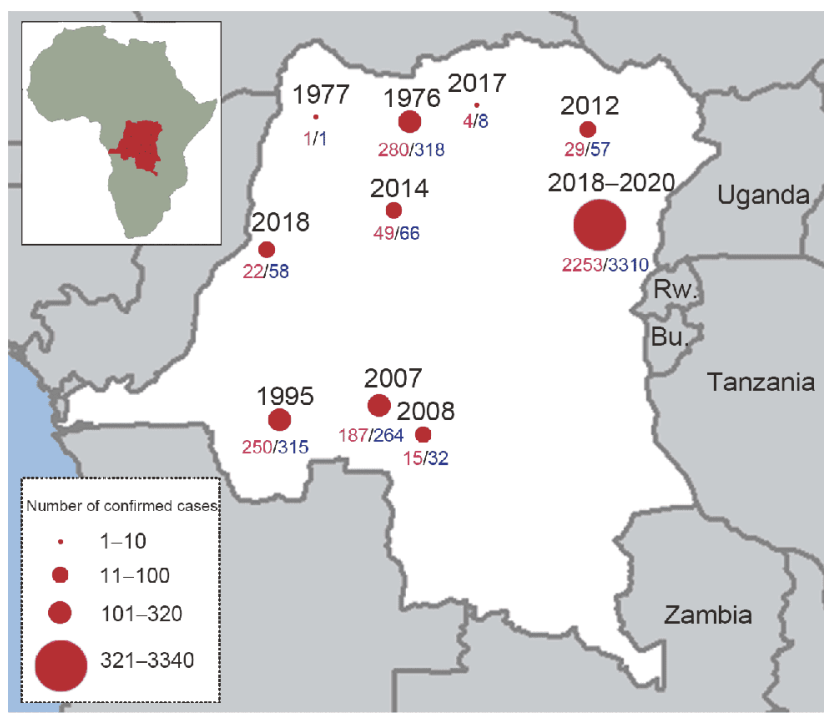

Figure 1 (Color online) Distribution of confirmed EVD cases and deaths in the Democratic Republic of Congo over the years. Deaths are highlighted in pink, and confirmed cases are highlighted in blue.

superior to ZMapp in reducing EVD mortality in randomized controlled trials of Ebola disease therapies (Mulangu et al., 2019). In addition, Ebola virus infection can induce a strong immune response and the generation of a cytokine storm. Viral RNA can exist in survivors for a long time. Characterization of immune responses after Ebola virus infection can facilitate the identification of useful immune markers (Zhao et al., 2017).

China has not only contributed toward controlling the outbreak but has also established a fixed BSL-3 laboratory in Sierra Leone during the Ebola outbreak in West Africa. Furthermore, it has actively responded to the Ebola outbreak in the DRC by providing financial aid, materials, and experts (Han et al., 2017; Wu, 2019; Zhang and Gao, 2014). The Chinese Center for Disease Control and Prevention has strengthened cooperation with Africa to promote Africa's health and to ensure global health security (Gao, 2019). China has become an important partner in global health. A public health specialist team has worked in the DRC during the Ebola epidemic in the Équateur province for a month in 2018. Furthermore, China supports the WHO's call for action on the outbreak.

National public health systems play a crucial role in responding to major outbreaks worldwide. Despite the current state of conflict, the recent Ebola outbreak in the DRC must be successfully contained. Governments, international organizations, and institutes have to maintain close ties with communities while responding positively. Key political and armed groups should unite to respond to and stop violence against health care facilities.

The famous Chinese biologist T.C. Tung once said that science respects facts, obeys truth, and will not yield to any pressure. There is no doubt that countries worldwide hope to 
curb the spread of the Ebola epidemic as soon as possible and promote efficient interventions to prevent Ebola. We need to deal with social problems from a sociological perspective, but natural science is the way to solve them. We must believe that as countries in the hardest hit areas continue to strengthen prevention and control efforts, as the pace of the world's assistance continues to speed up, humankind will win the war against the deadly Ebola virus by scientific means.

Compliance and ethics The author(s) declare that they have no conflict of interest.

\section{References}

Gao, G.F. (2019). China's outreach to the world: public health goes global. China CDC Weekly 1, 1-2.

Han, M., Gu, J., Gao, G.F., and Liu, W.J. (2017). China in action: National strategies to combat against emerging infectious diseases. Sci China Life Sci 60, 1383-1385.

Li, J.X., Hou, L.H., Meng, F.Y., Wu, S.P., Hu, Y.M., Liang, Q., Chu, K., Zhang, Z., Xu, J.J., Tang, R., et al. (2017). Immunity duration of a recombinant adenovirus type-5 vector-based Ebola vaccine and a homologous prime-boost immunisation in healthy adults in China: final report of a randomised, double-blind, placebo-controlled, phase 1 trial. Lancet glob Health 5, e324-e334.

Liu, W.J. (2016). On the ground in Western Africa: from the outbreak to the elapse of Ebola. Protein Cell 7, 621-623.
Mahase, E. (2019). Attacks on Ebola sites in DRC leave four workers dead. BMJ 367, 16750.

Maxmen, A. (2019a). Science under fire: Ebola researchers fight to test drugs and vaccines in a war zone. Nature 572, 16-17.

Maxmen, A. (2019b). Violence propels Ebola outbreak towards 1,000 cases. Nature 567, 153-154.

Moran, B. (2018). Fighting Ebola in conflict in the DR Congo. Lancet 392, $1295-1296$.

Mulangu, S., Dodd, L.E., Davey Jr., R.T., Tshiani Mbaya, O., Proschan, M., Mukadi, D., Lusakibanza Manzo, M., Nzolo, D., Tshomba Oloma, A., Ibanda, A., et al. (2019). A randomized, controlled trial of Ebola virus disease therapeutics. N Engl J Med 381, 2293-2303.

Murray, M.J. (2015). Ebola virus disease. Anesthesia Analgesia 121, 798 809.

Nguyen, V.K. (2019). An epidemic of suspicion—Ebola and Violence in the DRC. N Engl J Med 380, 1298-1299.

Ilunga Kalenga, O., Moeti, M., Sparrow, A., Nguyen, V.K., Lucey, D., and Ghebreyesus, T.A. (2019). The ongoing Ebola epidemic in the Democratic Republic of Congo, 2018-2019. N Engl J Med 381, 373383.

Suschak, J.J., and Schmaljohn, C.S. (2019). Vaccines against Ebola virus and Marburg virus: Recent advances and promising candidates. Human Vaccines Immunotherapeutics 15, 2359-2377.

Wu, G. (2019). Laboratory biosafety in China: Past, present, and future. BioSaf Health 1, 56-58.

Zhang, B.K., and Gao, G.F. (2014). A new chapter for China's public health security-aids offered to Africa to combat Ebola. Sci China Life Sci 58, 114-116.

Zhao, M., Zhang, H., Liu, K., Gao, G.F., and Liu, W.J. (2017). Human Tcell immunity against the emerging and re-emerging viruses. Sci China Life Sci 60, 1307-1316. 